Article

\title{
Passivity-Based Control of a Doubly Fed Induction Generator System under Unbalanced Grid Voltage Conditions
}

\author{
Jiawei Huang ${ }^{1, *} \mathbb{C}$, Honghua Wang ${ }^{1}$ and Chong Wang ${ }^{2}$ \\ 1 College of Energy and Electrical Engineering, Hohai University, Nanjing 211100, China; \\ wanghonghua@263.net \\ 2 Department of Electrical \& Computer Engineering, Iowa State University, Ames, IA 50011, USA; \\ wangc@iastate.edu \\ * Correspondence: huangjia920@gmail.com; Tel.: +86-137-7097-7431 \\ Academic Editor: Frede Blaabjerg \\ Received: 23 May 2017; Accepted: 31 July 2017; Published: 3 August 2017
}

\begin{abstract}
According to the theory of passivity-based control (PBC), this paper establishes a port-controlled Hamiltonian system with dissipation (PCHD) model for a doubly fed induction generator (DFIG) system under unbalanced grid voltage conditions and proposes a method of interconnection and damping assignment passivity-based control (IDA-PBC) of the system under such conditions. By using this method, the rotor-side converter and grid-side converter can be controlled simultaneously in order to improve fault ride-through capability of the DFIG system. Simulation results indicate that this IDA-PBC strategy effectively suppresses fluctuations of output current and power in the DFIG system during unbalanced grid voltage sag/swell, enhances dynamic performance, and improves the robustness of the system.
\end{abstract}

Keywords: doubly fed induction generator; grid voltage unbalance; fault ride-through; passivity-based control; port-controlled Hamiltonian system

\section{Introduction}

In recent decades, in response to the energy crisis and environmental pollution, people have continuously sought clean and renewable resources to replace fossil fuels, largely promoting the development of wind power technologies [1,2]. Among these technologies, the doubly fed induction generator (DFIG) system has been adopted in a large proportion of wind turbines, with benefits of small volume, low cost, and stable operation performance [3-5].

The DFIG system is characterized by its high-order, strong coupling, and non-linear behavior; the control method is relatively complicated. Usually, the stator-side of the system is connected to the grid directly while its rotor-side is connected to the grid via a back-to-back converter. The converter's capacity is relatively small and largely influenced by the status of the grid. Therefore, higher requirements are desired if DFIGs are to be constructed on a large scale and operated in grid-connected mode [6-9]. Though the PI regulator based vector control is commonly used and can ensure stable operation of DFIGs within certain range, it is not intrinsically robust, and it can be rather difficult to realize the overall stability of the system. Especially under unbalanced grid voltage conditions, the DFIG system is not effective enough to isolate its connection with the grid. As a result, the unbalanced grid voltage leads to unbalanced stator current and rotor current, causing stator winding and rotor winding to generate uneven heat and inducing pulsation in the torque of the generator, which results in oscillation of the power passing to the grid $[10,11]$. Meanwhile, the output current and power fluctuate at double the grid frequency in the synchronous frame; however, the PI regulator cannot 
realize zero steady-state error in this situation, which affects stable operation of the DFIG system and the grid. Currently, studies of DFIG systems under unbalanced grid voltage conditions are no longer limited to voltage sags. When a grid voltage sag occurs, switching the reactive compensation device in the wind power plant might lead to surplus of the reactive power, which causes the voltage to increase abruptly at the moment when the grid voltage is recovered. Moreover, sudden removal of a load in the wind power plant will also lead to grid voltage swell [12-14]. As a consequence, higher requirements are desired to control the DFIG system under unbalanced grid voltage conditions.

Passivity-based control (PBC) is a non-linear feedback control strategy aimed at ensuring overall stability. With the design principle being the energy balance of the system, it forces the total energy of the system to track desired energy function so that state variables of the system asymptotically converge towards equilibrium values [15]. The strategy of studying system control from the perspective of energy is greatly valued in the area of DFIG systems. PBC is mainly based on Euler-Lagrange equations or port-controlled Hamiltonian system with dissipation (PCHD) equations, where the latter are derived and developed from the former. Up to now, most of the literature discusses PBC of DFIG systems based on Euler-Lagrange equations while little research has been conducted on PBC using the PCHD model. Under normal grid conditions, [16] established an Euler-Lagrange model of DFIGs, based on which, the design of PBC law is proposed. In addition, [17] studied control strategies based on an Euler-Lagrange model of DFIGs under unbalanced grid voltage conditions. The study reported by [18] was performed on the control strategy based on a PCHD model of back-to-back converter in a permanent magnet synchronous generator system under normal grid conditions. Reference [19] presented an energy-based coordinated control of a DFIG system under normal grid conditions based on the theory of port-controlled Hamiltonian system. Furthermore, [20,21] discussed interconnection and damping assignment passivity-based control (IDA-PBC) methods of DFIGs under normal grid conditions. All these papers laid a foundation for further study of PBC of the DFIG system. However, during grid voltage unbalance, PCHD modeling and $\mathrm{PBC}$ analysis are different from those under normal grid conditions.

In this paper, a new PCHD model of DFIGs and grid-side converters in a DFIG system under unbalanced grid voltage conditions is established. Based on the PCHD model, with the idea of overall coordinated control, an IDA-PBC law is performed on both the rotor-side converter and grid-side converter to improve operation performance of the DFIG system under unbalanced grid voltage conditions.

\section{PCHD Modeling of a Doubly Fed Induction Generator (DFIG) System during Grid Voltage Unbalance}

To perform IDA-PBC of the system, a PCHD model of this system is desired. Definition of standard PCHD equations are given as [22,23]:

$$
\left\{\begin{array}{l}
\dot{x}=[J(x)-R(x)] \frac{\partial H}{\partial x}(x)+g(x) \mathbf{u} \\
y=g^{T}(x) \frac{\partial H}{\partial x}(x)
\end{array}\right.
$$

where $x \in R^{n}$ are the state variables of the system, $u \in R^{m}$ are the input variables, $y \in R^{m}$ are the output variables; the interconnection matrix $J(x)$ is a skew-symmetric matrix which represents interconnection structure inside the system; the damping matrix $R(x)$ is a positive semi-definite symmetric matrix which reflects the dissipation; the interconnection structure is also captured in the input matrix $g(x)$; the Hamiltonian function $H(x): R^{n} \rightarrow R$ represents the total energy of the system.

\subsection{PCHD Model of a DFIG}

When the grid voltage is unbalanced, DFIG systems are usually analyzed in the positive and negative synchronous reference frames. Then, the mathematical model of voltage and flux linkage of a DFIG can be expressed as [24]: 


$$
\begin{aligned}
& \left\{\begin{array}{l}
\boldsymbol{U}_{\mathrm{sdq}+}^{+}=R_{\mathrm{s}} I_{\mathrm{sdq}+}^{+}+\frac{\mathrm{d} \psi_{\mathrm{sdq}+}^{+}}{\mathrm{d} t}+\mathrm{j} \omega_{1} \psi_{\mathrm{sdq}+}^{+} \\
\boldsymbol{U}_{\mathrm{sdq}-}^{-}=R_{\mathrm{s}} \boldsymbol{I}_{\mathrm{sdq}-}^{-}+\frac{\mathrm{d} \psi_{\mathrm{sdq}-}^{-}}{\mathrm{d} t}-\mathrm{j} \omega_{1} \psi_{\mathrm{sdq}-}^{-} \\
\boldsymbol{U}_{\mathrm{rdq}+}^{+}=R_{\mathrm{r}} \boldsymbol{I}_{\mathrm{rdq}+}^{+}+\frac{\mathrm{d} \psi_{\mathrm{rd}+}^{+}}{\mathrm{d} t}+\mathrm{j} \omega_{\mathrm{slip}+} \boldsymbol{\psi}_{\mathrm{rdq}+}^{+} \\
\boldsymbol{U}_{\mathrm{rdq}-}^{-}=R_{\mathrm{r}} \boldsymbol{I}_{\mathrm{rdq}-}^{-}+\frac{\mathrm{d} \psi_{\mathrm{rd}{ }^{-}}^{-}}{\mathrm{d} t}+\mathrm{j} \omega_{\mathrm{slip}-} \boldsymbol{\psi}_{\mathrm{rdq}-}^{-}
\end{array}\right. \\
& \left\{\begin{array}{l}
\boldsymbol{\psi}_{\mathrm{sdq}+}^{+}=L_{\mathrm{s}} \boldsymbol{I}_{\mathrm{sdq}+}^{+}+L_{\mathrm{m}} \boldsymbol{I}_{\mathrm{rdq}+}^{+} \\
\boldsymbol{\psi}_{\mathrm{sdq}-}^{-}=L_{\mathrm{s}} \boldsymbol{I}_{\mathrm{sdq}-}^{-}+L_{\mathrm{m}} \boldsymbol{I}_{\mathrm{rdq}-}^{-} \\
\boldsymbol{\psi}_{\mathrm{rdq}+}^{+}=L_{\mathrm{r}} \boldsymbol{I}_{\mathrm{rdq}+}^{+}+L_{\mathrm{m}} \boldsymbol{I}_{\mathrm{sdq}+}^{+} \\
\boldsymbol{\psi}_{\mathrm{rdq}-}^{-}=L_{\mathrm{r}} \boldsymbol{I}_{\mathrm{rdq}-}^{-}+L_{\mathrm{m}} \boldsymbol{I}_{\mathrm{sdq}-}^{-}
\end{array}\right.
\end{aligned}
$$

where superscript,+- denote positive, negative synchronous reference frame, respectively; subscript ,+- individually represent positive, negative sequence component; subscript $s, r$ represent stator and rotor, respectively; subscript $d$, q individually denote synchronous $d$ and $q$ axis. While $\omega_{\text {slip }+}=$ $\omega_{1}-\omega_{\mathrm{r}}$ represents the slip angular frequency in the synchronous frame, $\omega_{\text {slip- }}=-\omega_{1}-\omega_{\mathrm{r}}$ is the slip angular frequency in the negative synchronous frame, where $\omega_{1}$ is the grid angular frequency, $\omega_{\mathrm{r}}$ is the rotor angular frequency. $R_{\mathrm{s}}, R_{\mathrm{r}}$ are resistances of the stator and rotor, respectively; $L_{\mathrm{s}}, L_{\mathrm{r}}$ are self-inductances of the stator and rotor, respectively; $L_{\mathrm{m}}$ is the mutual inductance. The electromagnetic torque and motion equation of a DFIG can be expressed as:

$$
\left\{\begin{array}{l}
T_{\mathrm{e}+}^{+}=n_{\mathrm{p}} L_{\mathrm{m}}\left(I_{\mathrm{sq}+}^{+} I_{\mathrm{rd}+}^{+}-I_{\mathrm{sd}+}^{+} I_{\mathrm{rq}+}^{+}\right) \\
T_{\mathrm{e}-}^{-}=n_{\mathrm{p}} L_{\mathrm{m}}\left(I_{\mathrm{sq}-}^{-} I_{\mathrm{rd}-}^{-}-I_{\mathrm{sd}-}^{-} I_{\mathrm{rq}-}^{-}\right) \\
T_{\mathrm{e}}=T_{\mathrm{e}+}^{+}+T_{\mathrm{e}-}^{-} \\
T_{\mathrm{m}}-T_{\mathrm{e}}=f \omega_{\mathrm{m}}+J_{\mathrm{m}} \dot{\omega}_{\mathrm{m}}
\end{array}\right.
$$

where $T_{\mathrm{e}}$ is the electromagnetic torque; $T_{\mathrm{m}}$ is the mechanical torque that passes to the generator shaft; $n_{\mathrm{p}}$ is the number of pole pairs of DFIG; $\omega_{\mathrm{m}}$ is the mechanical angular speed of the rotor; $f$ is the viscous friction coefficient of the rotor; $J_{\mathrm{m}}$ is the moment of inertia that casts onto the generator shaft.

Assume state variable of the DFIG $x_{\mathrm{R}}=\left[\psi_{\mathrm{sd}+}^{+} \psi_{\mathrm{sq}+}^{+} \psi_{\mathrm{rd}+}^{+} \psi_{\mathrm{rq}+}^{+} \psi_{\mathrm{sd}-}^{-} \psi_{\mathrm{sq}-}^{-} \psi_{\mathrm{rd}-}^{-} \psi_{\mathrm{rq}-}^{-}-J_{\mathrm{m}} \omega_{\mathrm{m}}\right]^{\mathrm{T}}$, input variable $\boldsymbol{u}_{\mathrm{R}}=\left[u_{\mathrm{sd}+}^{+} u_{\mathrm{sq}+}^{+} u_{\mathrm{rd}+}^{+} u_{\mathrm{rq}+}^{+} u_{\mathrm{sd}-}^{-} u_{\mathrm{sq}-}^{-} u_{\mathrm{rd}-}^{-} u_{\mathrm{rq}-}^{-} 0\right]^{\mathrm{T}}$ and output variable $\boldsymbol{y}_{\mathrm{R}}=\left[i_{\mathrm{sd}+}^{+} i_{\mathrm{sq}+}^{+}\right.$ $\left.i_{\mathrm{rd}+}^{+} i_{\mathrm{rq}+}^{+} i_{\mathrm{sd}-}^{-} i_{\mathrm{sq}-}^{-} i_{\mathrm{rd}-}^{-} i_{\mathrm{rq}-}^{-}-\omega_{\mathrm{m}}\right]^{\mathrm{T}}$.

Given energy storage function of the DFIG:

$$
H_{\mathrm{R}}\left(x_{\mathrm{R}}\right)=\frac{1}{2} \boldsymbol{x}_{\mathrm{R}}^{T} \boldsymbol{M}_{\mathrm{R}}^{-1} \boldsymbol{x}_{\mathrm{R}}
$$

where $\boldsymbol{M}_{\mathrm{R}}=\operatorname{diag}\left(\boldsymbol{M}_{1}, \boldsymbol{M}_{2}, J_{\mathrm{m}}\right), \boldsymbol{M}_{1}=\boldsymbol{M}_{2}=\left[\begin{array}{cc}L_{\mathrm{s}} \boldsymbol{I} & L_{\mathrm{m}} \boldsymbol{I} \\ L_{\mathrm{m}} \boldsymbol{I} & L_{\mathrm{r}} \boldsymbol{I}\end{array}\right], \boldsymbol{I}$ is a second-order unit matrix. Then, the PCHD model of DFIGs in a DFIG system under unbalanced grid voltage conditions is:

$$
\left\{\begin{array}{l}
\dot{x}_{R}=\left[J_{R}\left(x_{R}\right)-R_{R}\left(x_{R}\right)\right] \frac{\partial H_{R}}{\partial x_{R}}\left(x_{R}\right)+W_{R}+g_{R}\left(x_{R}\right) u_{R} \\
y_{R}=g_{R}\left(x_{R}\right)^{T} \frac{\partial H_{R}}{\partial x_{R}}\left(x_{R}\right)
\end{array}\right.
$$

where, $\boldsymbol{J}_{\mathrm{R}}\left(\boldsymbol{x}_{\mathrm{R}}\right)=\left[\begin{array}{ccc}\boldsymbol{J}_{\mathrm{R} 1} & \mathbf{0}_{4 \times 4} & -\boldsymbol{J}_{\mathrm{R} 3}^{T} \\ \mathbf{0}_{4 \times 4} & \boldsymbol{J}_{\mathrm{R} 2} & -\boldsymbol{J}_{\mathrm{R} 4}^{T} \\ \boldsymbol{J}_{\mathrm{R} 3} & \boldsymbol{J}_{\mathrm{R} 4} & 0\end{array}\right], \boldsymbol{J}_{\mathrm{R} 1}=-\boldsymbol{J}_{\mathrm{R} 2}=\left[\begin{array}{cc}\omega_{1} L_{s} \boldsymbol{Z} & \omega_{1} L_{m} \boldsymbol{Z} \\ \omega_{1} L_{m} \mathbf{Z} & \omega_{1} L_{r} \boldsymbol{Z}\end{array}\right], \boldsymbol{Z}=\left[\begin{array}{cc}0 & 1 \\ -1 & 0\end{array}\right]$, $J_{\mathrm{R} 3}=\left[\begin{array}{llll}0 & 0 & n_{\mathrm{p}} \psi_{\mathrm{rq}+}^{+}-n_{\mathrm{p}} \psi_{\mathrm{rd}+}^{+}\end{array}\right], J_{\mathrm{R} 4}=\left[\begin{array}{llll}0 & 0 & n_{\mathrm{p}} \psi_{\mathrm{rq}-}^{-}-n_{\mathrm{p}} \psi_{\mathrm{rd}-}^{-}\end{array}\right], R_{\mathrm{R}}\left(x_{\mathrm{R}}\right)=\operatorname{diag}\left(R_{\mathrm{s}}, R_{\mathrm{s}}, R_{\mathrm{r}}, R_{\mathrm{r}}, R_{\mathrm{s}}, R_{\mathrm{s}}, R_{\mathrm{r}}, R_{\mathrm{r}}\right.$, $-f), \boldsymbol{W}_{\mathrm{R}}=\left[\mathbf{0}_{1 \times 8}-T_{\mathrm{m}}\right]^{\mathrm{T}}, \boldsymbol{g}_{\mathrm{R}}\left(x_{\mathrm{R}}\right)$ is a ninth-order unit matrix. 


\subsection{PCHD Model of a Grid-Side Converter}

Under unbalanced grid voltage conditions, the mathematical model of a grid-side converter in DFIG systems can be expressed as [25]:

$$
\left\{\begin{array}{l}
U_{\mathrm{gdq}+}^{+}=R_{\mathrm{g}} I_{\mathrm{gdq}+}^{+}+\mathrm{j} \omega_{1} L_{\mathrm{g}} I_{\mathrm{gdq}+}^{+}+V_{\mathrm{gdq}+}^{+}+L_{\mathrm{g}} \frac{\mathrm{d} I_{\mathrm{gdq}+}^{+}}{\mathrm{d} t} \\
\boldsymbol{U}_{\mathrm{gdq}-}^{-}=R_{\mathrm{g}} I_{\mathrm{gdq}-}^{-}-\mathrm{j} \omega_{1} L_{\mathrm{g}} I_{\mathrm{gdq}-}^{-}+V_{\mathrm{gdq}-}^{-}+L_{\mathrm{g}} \frac{\mathrm{d} I_{\mathrm{gdq}-}^{-}}{\mathrm{d} t}
\end{array}\right.
$$

where $R_{\mathrm{g}}, L_{\mathrm{g}}$ are the respective resistance and induction of the input reactor. Since the stator of the DFIG is connected to the grid, then, $\boldsymbol{U}_{\mathrm{sdq}+}^{+}=\boldsymbol{U}_{\mathrm{gdq}+}^{+}, \boldsymbol{U}_{\mathrm{sdq}-}^{-}=\boldsymbol{U}_{\mathrm{gdq}-}^{-}$.

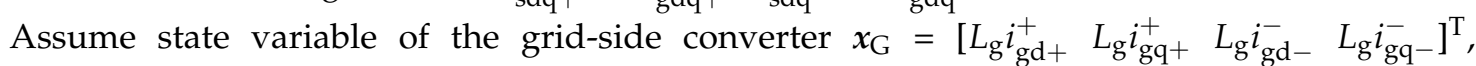
input variable $u_{\mathrm{G}}=\left[u_{\mathrm{gd}+}^{+}-v_{\mathrm{gd}+}^{+} u_{\mathrm{gq}+}^{+}-v_{\mathrm{gq}+}^{+} u_{\mathrm{gd}-}^{-}-v_{\mathrm{gd}-}^{-} u_{\mathrm{gq}-}^{-}-v_{\mathrm{gq}-}^{-}\right]^{\mathrm{T}}$ and output variable $y_{\mathrm{G}}=\left[i_{\mathrm{gd}+}^{+} i_{\mathrm{gq}+}^{+} i_{\mathrm{gd}-}^{-} i_{\mathrm{gq}-}^{-}\right]^{\mathrm{T}}$.

Given the energy storage function of the grid-side converter:

$$
H_{\mathrm{G}}\left(x_{\mathrm{G}}\right)=\frac{1}{2} x_{\mathrm{G}}{ }^{T} \boldsymbol{M}_{\mathrm{G}}{ }^{-1} x_{\mathrm{G}}
$$

where $\boldsymbol{M}_{\mathrm{G}}=\operatorname{diag}\left(L_{\mathrm{g}}, L_{\mathrm{g}}, L_{\mathrm{g}}, L_{\mathrm{g}}\right)$. Then, the PCHD model of a grid-side converter in DFIG systems under unbalanced grid voltage conditions can be expressed as:

$$
\left\{\begin{array}{l}
\dot{x}_{\mathrm{G}}=\left[J_{\mathrm{G}}\left(x_{\mathrm{G}}\right)-\boldsymbol{R}_{\mathrm{G}}\left(x_{\mathrm{G}}\right)\right] \frac{\partial H_{\mathrm{G}}}{\partial x_{\mathrm{G}}}\left(x_{\mathrm{G}}\right)+\boldsymbol{g}_{\mathrm{G}}\left(x_{\mathrm{G}}\right) \boldsymbol{u}_{\mathrm{G}} \\
y_{\mathrm{G}}=g_{\mathrm{G}}\left(x_{\mathrm{G}}\right)^{T} \frac{\partial H_{\mathrm{G}}}{\partial x_{\mathrm{G}}}\left(x_{\mathrm{G}}\right)
\end{array}\right.
$$

where $J_{\mathrm{G}}\left(x_{\mathrm{G}}\right)=\left[\begin{array}{cc}\omega_{1} L_{\mathrm{g}} \mathrm{z} & 0 \\ 0 & -\omega_{1} L_{\mathrm{g}} \mathrm{Z}\end{array}\right], \boldsymbol{R}_{\mathrm{G}}\left(\boldsymbol{x}_{\mathrm{G}}\right)=\operatorname{diag}\left(R_{\mathrm{g}}, R_{\mathrm{g}}, R_{\mathrm{g}}, R_{\mathrm{g}}\right), \boldsymbol{g}_{\mathrm{G}}\left(\boldsymbol{x}_{\mathrm{G}}\right)$ is a fourth-order unit matrix.

In conclusion, Equations (6) and (9) are the PCHD model of a DFIG system under unbalanced grid voltage conditions.

\section{IDA-PBC of a DFIG System during Grid Voltage Unbalance}

From principles of IDA-PBC, it can be seen that for Equation (1), proper interconnection configuration matrix $J_{\mathrm{c}}(x)$ and damping configuration matrix $\boldsymbol{R}_{\mathrm{c}}(x)$ are desired to change the energy function of the original system so that the following equation is valid [26]:

$$
\left\{\left[J(x)+J_{\mathrm{c}}(x)\right]-\left[R(x)+R_{\mathrm{c}}(x)\right]\right\} \frac{\partial H_{\mathrm{c}}}{\partial x}(x)=-\left[J_{\mathrm{c}}(x)-\boldsymbol{R}_{\mathrm{c}}(x)\right] \frac{\partial \mathrm{H}}{\partial x}(x)+g(x) \mathrm{u}
$$

after introducing control, the system is close-looped and stabilized, which turns out to be a PCHD system with dissipation of the form:

$$
\dot{x}=\left[J_{\mathrm{d}}(x)-R_{\mathrm{d}}(x)\right] \frac{\partial H_{\mathrm{d}}}{\partial x}(x)
$$

The energy function of this closed-loop system is $H_{\mathrm{d}}=H+H_{\mathrm{c}}$, where $H_{\mathrm{c}}$ represents energy that is injected into the system through control. $J_{\mathrm{d}}(x)=J(x)+J_{\mathrm{c}}(x)$ should be a skew-symmetric matrix; $\boldsymbol{R}_{\mathrm{d}}(\boldsymbol{x})=\boldsymbol{R}(\boldsymbol{x})+\boldsymbol{R}_{c}(\boldsymbol{x})$ should be a positive semi-definite symmetric matrix. 


\subsection{IDA-PBC Law of a DFIG}

To reserve generality, the interconnection configuration matrix of DFIGs in a DFIG system under unbalanced grid voltage conditions is defined as $\boldsymbol{J}_{\mathrm{Rc}}\left(\boldsymbol{x}_{\mathrm{R}}\right)=\left[\begin{array}{ccc}\boldsymbol{J}_{\mathrm{Rc} 1} & \mathbf{0}_{4 \times 4} & -\boldsymbol{J}_{\mathrm{Rc} 3}^{T} \\ \mathbf{0}_{4 \times 4} & \boldsymbol{J}_{\mathrm{Rc} 2} & -\boldsymbol{J}_{\mathrm{Rc4}}^{T} \\ \boldsymbol{J}_{\mathrm{Rc} 3} & \boldsymbol{J}_{\mathrm{Rc} 4} & 0\end{array}\right]$, where $J_{\mathrm{R} 1}=\left[\begin{array}{cccc}0 & J_{\mathrm{R} 1+} & 0 & J_{\mathrm{R} 2+} \\ -J_{\mathrm{R} 1+} & 0 & -J_{\mathrm{R} 3+} & 0 \\ 0 & J_{\mathrm{R} 3+} & 0 & J_{\mathrm{R} 4+} \\ -J_{\mathrm{R} 2+} & 0 & -J_{\mathrm{R} 4+} & 0\end{array}\right], \quad J_{\mathrm{R} 22}=\left[\begin{array}{cccc}0 & J_{\mathrm{R} 1-} & 0 & J_{\mathrm{R} 2-} \\ -J_{\mathrm{R} 1-} & 0 & -J_{\mathrm{R} 3-} & 0 \\ 0 & J_{\mathrm{R} 3-} & 0 & J_{\mathrm{R} 4-} \\ -J_{\mathrm{R} 2-} & 0 & -J_{\mathrm{R} 4-} & 0\end{array}\right]$, $J_{\mathrm{R} 3}=\left[\begin{array}{lll}0 & 0 & J_{\mathrm{R} 5+}-J_{\mathrm{R} 6+}\end{array}\right], J_{\mathrm{R} 4}=\left[\begin{array}{llll}0 & 0 & J_{\mathrm{R} 5-}-J_{\mathrm{R} 6-}\end{array}\right]$. The damping configuration matrix is given as $\boldsymbol{R}_{\mathrm{Rc}}\left(\boldsymbol{x}_{\mathrm{R}}\right)=\operatorname{diag}\left(r_{\mathrm{r} 1+}, r_{\mathrm{r} 2+}, r_{\mathrm{r} 3+}, r_{\mathrm{r} 4+}, r_{\mathrm{r} 1-}, r_{\mathrm{r} 2-}, r_{\mathrm{r} 3-}, r_{\mathrm{r} 4-}, 0\right)$. The energy function of the closed-loop DFIG system after applying IDA-PBC is:

$$
H_{\mathrm{Rd}}\left(\boldsymbol{x}_{\mathrm{R}}\right)=H_{\mathrm{R}}\left(\boldsymbol{x}_{\mathrm{R}}\right)+H_{\mathrm{Rc}}\left(\boldsymbol{x}_{\mathrm{R}}\right)=\frac{1}{2}\left(\boldsymbol{x}_{\mathrm{R}}-\boldsymbol{x}_{\mathrm{R}}^{*}\right)^{T} \boldsymbol{M}_{\mathrm{R}}{ }^{-1}\left(\boldsymbol{x}_{\mathrm{R}}-\boldsymbol{x}_{\mathrm{R}}^{*}\right)
$$

where superscript ${ }^{*}$ represents the desired equilibrium point; $H_{\mathrm{Rc}}\left(x_{\mathrm{R}}\right)$ is the energy injected to the system though control. From Equation (10), the PBC law of a DFIG in DFIG systems under unbalanced grid voltage conditions is:

$$
\boldsymbol{u}_{\mathrm{R}}=-\left[\boldsymbol{J}_{\mathrm{Rd}}\left(x_{\mathrm{R}}\right)-\boldsymbol{R}_{\mathrm{Rd}}\left(x_{\mathrm{R}}\right)\right] \boldsymbol{M}_{\mathrm{R}}^{-1} \boldsymbol{x}_{\mathrm{R}}^{*}+\left[\boldsymbol{J}_{\mathrm{Rc}}\left(\boldsymbol{x}_{\mathrm{R}}\right)-\boldsymbol{R}_{\mathrm{Rc}}\left(\boldsymbol{x}_{\mathrm{R}}\right)\right] \boldsymbol{M}_{\mathrm{R}}^{-1} \boldsymbol{x}_{\mathrm{R}}-\boldsymbol{W}_{\mathrm{R}}
$$

After rearrangement, it can be expressed as:

$$
\left\{\begin{aligned}
u_{\mathrm{rd}+}^{+} & =R_{\mathrm{r}} i_{\mathrm{rd}+}^{+*}+n_{\mathrm{p}} \omega_{\mathrm{m}}^{*} \psi_{\mathrm{rq}+}^{+}-\omega_{1} \psi_{\mathrm{rq}+}^{+*}+r_{\mathrm{r} 3+}\left(i_{\mathrm{rd}+}^{+*}-i_{\mathrm{rd}+}^{+}\right) \\
& -J_{\mathrm{R} 3+}\left(i_{\mathrm{sq}+}^{+*}-i_{\mathrm{sq}+}^{+}\right)-J_{\mathrm{R} 4+}\left(i_{\mathrm{rq}+}^{+*}-i_{\mathrm{rq}+}^{+}\right)+J_{\mathrm{R} 5+}\left(\omega_{\mathrm{m}}^{*}-\omega_{\mathrm{m}}\right) \\
u_{\mathrm{rq}+}^{+} & =R_{\mathrm{r}} i_{\mathrm{rq}+}^{+*}-n_{\mathrm{p}} \omega_{\mathrm{m}}^{*} \psi_{\mathrm{rd}+}^{+}+\omega_{1} \psi_{\mathrm{rd}+}^{+*}+r_{\mathrm{r} 4+}\left(i_{\mathrm{rq}+}^{+*}-i_{\mathrm{rq}+}^{+}\right) \\
& +J_{\mathrm{R} 2+}\left(i_{\mathrm{sd}+}^{+*}-i_{\mathrm{sd}+}^{+}\right)+J_{\mathrm{R} 4+}\left(i_{\mathrm{rd}+}^{+*}-i_{\mathrm{rd}+}^{+}\right)-J_{\mathrm{R} 6+}\left(\omega_{\mathrm{m}}^{*}-\omega_{\mathrm{m}}\right) \\
u_{\mathrm{rd}-}^{-} & =R_{\mathrm{r}} i_{\mathrm{rd}-}^{-*}+n_{\mathrm{p}} \omega_{\mathrm{m}}^{*} \psi_{\mathrm{rq}-}^{-}+\omega_{1} \psi_{\mathrm{rq}-}^{-*}+r_{\mathrm{r} 3-}\left(i_{\mathrm{rd}-}^{-*}-i_{\mathrm{rd}-}^{-}\right) \\
& -J_{\mathrm{R} 3-}\left(i_{\mathrm{sq}-}^{-*}-i_{\mathrm{sq}-}^{-}\right)-J_{\mathrm{R} 4-}\left(i_{\mathrm{rq}-}^{-*}-i_{\mathrm{rq}-}^{-}\right)+J_{\mathrm{R} 5-}\left(\omega_{\mathrm{m}}^{*}-\omega_{\mathrm{m}}\right) \\
u_{\mathrm{rq}-}^{-} & =R_{\mathrm{r}} i_{\mathrm{rq}-}^{-*}-n_{\mathrm{p}} \omega_{\mathrm{m}}^{*} \psi_{\mathrm{rd}-}^{-}-\omega_{1} \psi_{\mathrm{rd}-}^{-*}+r_{\mathrm{r} 4-}\left(i_{\mathrm{rq}-}^{-*}-i_{\mathrm{rq}-}^{-}\right) \\
& +J_{\mathrm{R} 2-}\left(i_{\mathrm{sd}-}^{-*}-i_{\mathrm{sd}-}^{-}\right)+J_{\mathrm{R} 4-}\left(i_{\mathrm{rd}-}^{-*}-i_{\mathrm{rd}-}^{-}\right)-J_{\mathrm{R} 6-}\left(\omega_{\mathrm{m}}^{*}-\omega_{\mathrm{m}}\right)
\end{aligned}\right.
$$

\subsection{IDA-PBC Law of a Grid-Side Converter}

The interconnection configuration matrix of a grid-side converter in a DFIG system under unbalanced grid voltage conditions is defined as $J_{\mathrm{Gc}}\left(x_{\mathrm{G}}\right)=\left[\begin{array}{cc}J_{\mathrm{g}+} \boldsymbol{Z} & \mathbf{0}_{2 \times 2} \\ \mathbf{0}_{2 \times 2} & J_{\mathrm{g}-} \boldsymbol{Z}\end{array}\right]$. The damping configuration matrix is $\boldsymbol{R}_{\mathrm{Gc}}\left(\boldsymbol{x}_{\mathrm{G}}\right)=\operatorname{diag}\left(r_{\mathrm{g} 1+}, r_{\mathrm{g} 2+}, r_{\mathrm{g} 3+}, r_{\mathrm{g} 4+}, r_{\mathrm{g} 1-}, r_{\mathrm{g} 2-}, r_{\mathrm{g} 3-}, r_{\mathrm{g} 4-}, 0\right)$. The energy function of the closed-loop grid-side converter system after introduction of IDA-PBC is:

$$
H_{\mathrm{Gd}}\left(x_{\mathrm{G}}\right)=H_{\mathrm{G}}\left(x_{\mathrm{G}}\right)+H_{\mathrm{Gc}}\left(x_{\mathrm{G}}\right)=\frac{1}{2}\left(x_{\mathrm{G}}-x_{\mathrm{G}}^{*}\right)^{T} \boldsymbol{M}_{\mathrm{G}}{ }^{-1}\left(x_{\mathrm{G}}-x_{\mathrm{G}}^{*}\right)
$$

where $H_{\mathrm{Gc}}\left(x_{\mathrm{G}}\right)$ represents energy that is injected into this system through control; $x_{\mathrm{G}}^{*}$ is the desired equilibrium point of this system. From Equation (10), the PBC law of a grid-side converter in a DFIG system under unbalanced grid voltage conditions is obtained: 


$$
\boldsymbol{u}_{\mathrm{G}}=-\left[\boldsymbol{J}_{\mathrm{Gd}}\left(x_{\mathrm{G}}\right)-\boldsymbol{R}_{\mathrm{Gd}}\left(x_{\mathrm{G}}\right)\right] \boldsymbol{M}_{\mathrm{G}}{ }^{-1} \boldsymbol{x}_{\mathrm{G}}^{*}+\left[\boldsymbol{J}_{\mathrm{Gc}}\left(x_{\mathrm{G}}\right)-\boldsymbol{R}_{\mathrm{Gc}}\left(x_{\mathrm{G}}\right)\right] \boldsymbol{M}_{\mathrm{G}}{ }^{-1} \boldsymbol{x}_{\mathrm{G}}
$$

After rearrangement, it can be expressed as:

$$
\left\{\begin{array}{c}
v_{\mathrm{gd}+}^{+}=u_{\mathrm{gd}+}^{+}-R_{\mathrm{g}} i_{\mathrm{gd}+}^{+*}+\omega_{1} L_{\mathrm{gg}} i_{\mathrm{gq}+}^{+*}-r_{\mathrm{g} 1+}\left(i_{\mathrm{gd}+}^{+*}-i_{\mathrm{gd}+}^{+}\right)+J_{\mathrm{g}+}\left(i_{\mathrm{gq}+}^{+*}-i_{\mathrm{gq}+}^{+}\right) \\
v_{\mathrm{gq}+}^{+}=u_{\mathrm{gq}+}^{+}-R_{\mathrm{g}} i_{\mathrm{gq}+}^{+*}-\omega_{1} L_{\mathrm{g}} i_{\mathrm{gd}+}^{+*}-r_{\mathrm{g} 2+}\left(i_{\mathrm{gq}+}^{+*}-i_{\mathrm{gq}+}^{+}\right)-J_{\mathrm{g}+}\left(i_{\mathrm{gd}+}^{+*}-i_{\mathrm{gd}+}^{+}\right) \\
v_{\mathrm{gd}-}^{-}=u_{\mathrm{gd}-}^{-}-R_{\mathrm{g}} i_{\mathrm{gd}-}^{-*}-\omega_{1} L_{\mathrm{gg}} i_{\mathrm{gq}-}^{-*}-r_{\mathrm{g} 1-}\left(i_{\mathrm{gd}-}^{-*}-i_{\mathrm{gd}-}^{-}\right)+J_{\mathrm{g}-}\left(i_{\mathrm{gq}-}^{-*}-i_{\mathrm{gq}-}^{-}\right) \\
v_{\mathrm{gq}-}^{-}=u_{\mathrm{gq}-}^{-}-R_{\mathrm{g}} i_{\mathrm{gq}-}^{-*}+\omega_{1} L_{\mathrm{g}} i_{\mathrm{gd}-}^{-*}-r_{\mathrm{g} 2-}\left(i_{\mathrm{gq}-}^{-*}-i_{\mathrm{gq}-}^{-}\right)-J_{\mathrm{g}-}\left(i_{\mathrm{gd}-}^{-*}-i_{\mathrm{gd}-}^{-}\right)
\end{array}\right.
$$

In conclusion, Equations (14) and (17) are the IDA-PBC laws of a DFIG system under unbalanced grid voltage conditions.

\section{Simulation Analysis of IDA-PBC of a DFIG System during Grid Voltage Unbalance}

To verify the feasibility of the proposed IDA-PBC law in a DFIG system under unbalanced grid voltage conditions, the system model is constructed in Simulink of MATLAB as well as toolbox of SimPowerSystem to carry out simulation studies. The main parameters are as follows: rated power of the DFIG is $2 \mathrm{MW}$, voltage of the stator is $680 \mathrm{~V}$, the grid frequency is $50 \mathrm{~Hz}$, resistance of the stator is 0.0108 p.u., resistance of the rotor is 0.0121 p.u., stator induction is 2.464 p.u., rotor induction is 3.472 p.u., and the grid voltage oriented space vector pulse width modulation (SVPWM) is applied. A structure scheme of the system is shown in Figure 1.

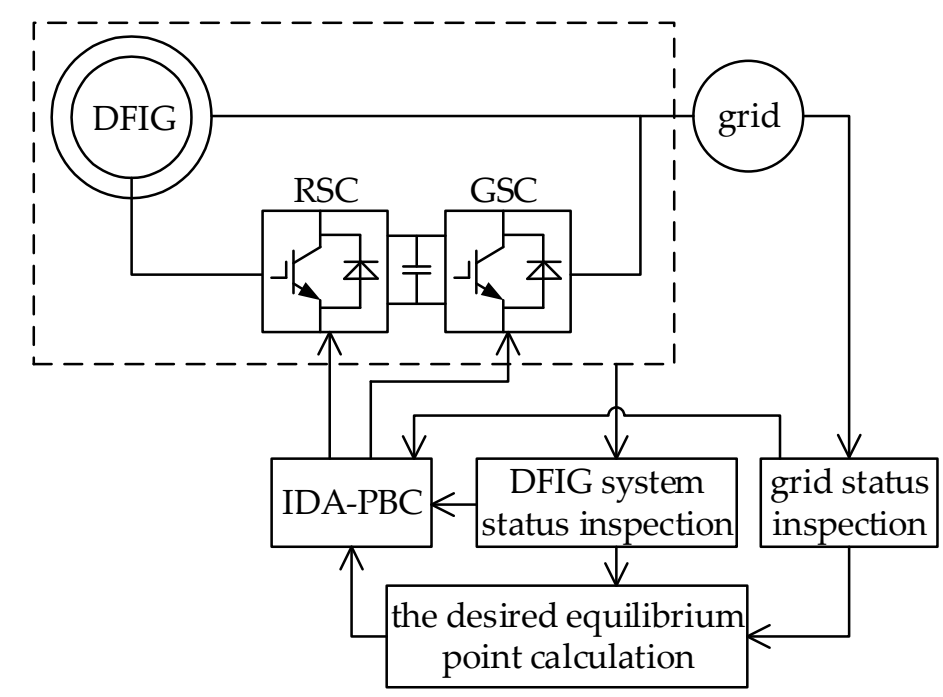

Figure 1. Structure scheme of doubly fed induction generator (DFIG) system with IDA-PBC method.

By status inspection of the grid and the DFIG system, real-time state variables of the grid and the DFIG system are obtained, and the desired equilibrium point of the system is calculated based on these variables. Meanwhile, IDA-PBC of the DFIG system is realized according to these state variables and the desired equilibrium point.

Assume voltage phase A of the grid drops to 0.8 p.u. at $2 \mathrm{~s}$ and abruptly rises to 1.2 p.u. at $2.6 \mathrm{~s}$, while voltage phases B and C are maintained at 1 p.u. continuously, which are shown in Figure 2. 

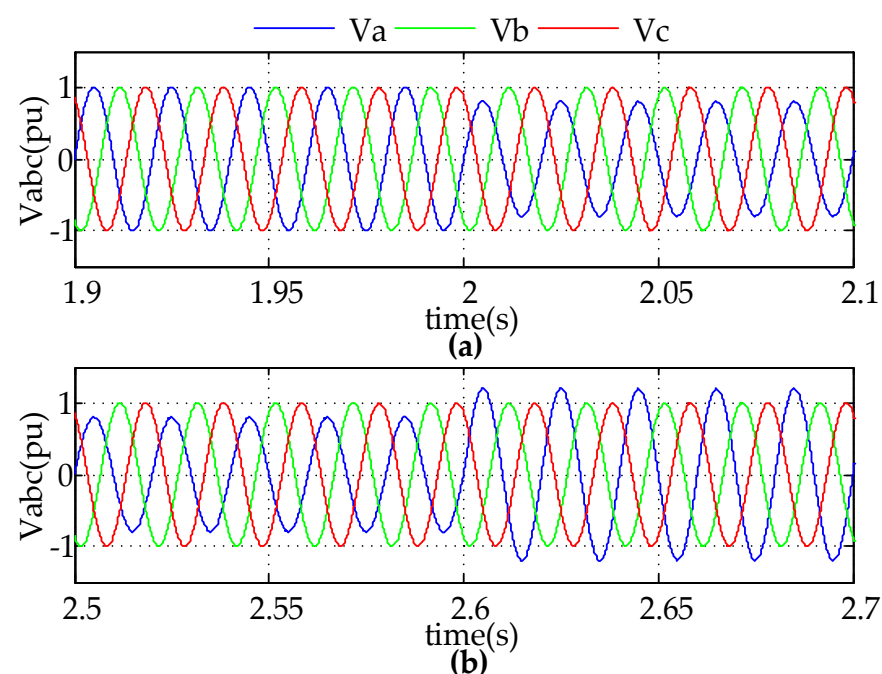

Figure 2. The grid voltage: (a) Voltage phase A drops from 1 p.u. to 0.8 p.u. at 2 s; (b) Voltage phase A rises from 0.8 p.u. to 1.2 p.u. at $2.6 \mathrm{~s}$.

\subsection{Influence of Grid Voltage Unbalance in a DFIG System}

Under unbalanced grid voltage conditions, the output current of the stator, rotor and grid-side converter in a DFIG system will have negative sequence components, which means the output current will fluctuate at double the grid frequency in the synchronous frame. Unbalanced current leads to unbalanced power. The power relationship of a DIFG system under unbalanced grid voltage conditions can be expressed as [27]:

$$
\left[\begin{array}{c}
P_{\mathrm{s} 0} \\
Q_{\mathrm{s} 0} \\
P_{\mathrm{ssin} 2} \\
P_{\mathrm{scos} 2} \\
Q_{\mathrm{ssin} 2} \\
Q_{\mathrm{scos} 2}
\end{array}\right]=\left[\begin{array}{cccc}
u_{\mathrm{sd}+}^{+} & u_{\mathrm{sq}+}^{+} & u_{\mathrm{sd}-}^{-} & u_{\mathrm{sq}-}^{-} \\
u_{\mathrm{sq}+}^{+} & -u_{\mathrm{sd}+}^{+} & u_{\mathrm{sq}-}^{-} & -u_{\mathrm{sd}-}^{-} \\
u_{\mathrm{sq}-}^{-} & -u_{\mathrm{sd}-}^{-} & -u_{\mathrm{sq}+}^{+} & u_{\mathrm{sd}+}^{+} \\
u_{\mathrm{sd}-}^{-} & u_{\mathrm{sq}-}^{-} & u_{\mathrm{sd}+}^{+} & u_{\mathrm{sq}+}^{+} \\
-u_{\mathrm{sd}-}^{-} & -u_{\mathrm{sq}-}^{-} & u_{\mathrm{sd}+}^{+} & u_{\mathrm{sq}+}^{+} \\
u_{\mathrm{sq}-}^{-} & -u_{\mathrm{sd}-}^{-} & u_{\mathrm{sq}+}^{+} & -u_{\mathrm{sd}+}^{+}
\end{array}\right]\left[\begin{array}{c}
i_{\mathrm{sd}+}^{+} \\
i_{\mathrm{sq}+}^{+} \\
i_{\mathrm{sd}-}^{-} \\
i_{\mathrm{sq}-}^{-}
\end{array}\right]
$$

and

$$
\left[\begin{array}{c}
P_{\mathrm{g} 0} \\
Q_{\mathrm{g} 0} \\
P_{\mathrm{gsin} 2} \\
P_{\mathrm{gcos} 2} \\
Q_{\mathrm{gsin} 2} \\
Q_{\mathrm{gcos} 2}
\end{array}\right]=\left[\begin{array}{cccc}
u_{\mathrm{gd}+}^{+} & u_{\mathrm{gq}+}^{+} & u_{\mathrm{gd}-}^{-} & u_{\mathrm{gq}-}^{-} \\
u_{\mathrm{gq}+}^{+} & -u_{\mathrm{gd}+}^{+} & u_{\mathrm{gq}-}^{-} & -u_{\mathrm{gd}-}^{-} \\
u_{\mathrm{gq}-}^{-} & -u_{\mathrm{gd}-}^{-} & -u_{\mathrm{gq}+}^{+} & u_{\mathrm{gd}+}^{+} \\
u_{\mathrm{gd}-}^{-} & u_{\mathrm{gq}-}^{-} & u_{\mathrm{gd}+}^{+} & u_{\mathrm{gq}+}^{+} \\
-u_{\mathrm{gd}-}^{-} & -u_{\mathrm{gq}-}^{-} & u_{\mathrm{gd}+}^{+} & u_{\mathrm{gq}+}^{+} \\
u_{\mathrm{gq}-}^{-} & -u_{\mathrm{gd}-}^{-} & u_{\mathrm{gq}+}^{+} & -u_{\mathrm{gd}+}^{+}
\end{array}\right]\left[\begin{array}{c}
i_{\mathrm{gd}+}^{+} \\
i_{\mathrm{gq}+}^{+} \\
i_{\mathrm{gd}-}^{-} \\
i_{\mathrm{gq}-}^{-}
\end{array}\right]
$$

where $P_{\mathrm{s} 0}$ and $Q_{\mathrm{s} 0}$ represent equilibrium components of active and reactive power outputs of the stator, respectively; $P_{\mathrm{g} 0}$ and $Q_{\mathrm{g} 0}$ represent equilibrium components of active and reactive power outputs of the grid-side converter, respectively. However, the existence of $P_{\mathrm{ssin} 2}, P_{\mathrm{scos} 2}, Q_{\mathrm{ssin} 2}, Q_{\mathrm{scos} 2}, P_{\mathrm{gsin} 2}$, $P_{\mathrm{gcos} 2}, Q_{\mathrm{gsin} 2}$ and $Q_{\mathrm{gcos} 2}$ indicates that there is fluctuation component at a double grid frequency in each power output in the DFIG system.

Figures 3 and 4 show the influences of grid voltage unbalance on the output current and power of a DFIG system, respectively. It is clear that when PI control in the synchronous frame is adopted, stator current (active component $i_{\mathrm{sd}}$, reactive component $i_{\mathrm{sq}}$ ) and grid-side converter current (active component $i_{\mathrm{gd}}$, reactive component $i_{\mathrm{gq}}$ ) of the DFIG system as well as each power (stator active power $P_{\mathrm{s}}$, stator reactive power $Q_{\mathrm{s}}$, grid-side converter active power $P_{\mathrm{g}}$, grid-side converter reactive 
power $Q_{\mathrm{g}}$ ) that pass to the grid will all show apparent fluctuations at a double grid frequency, which influences the continuous operation capability of a DFIG system under fault conditions.
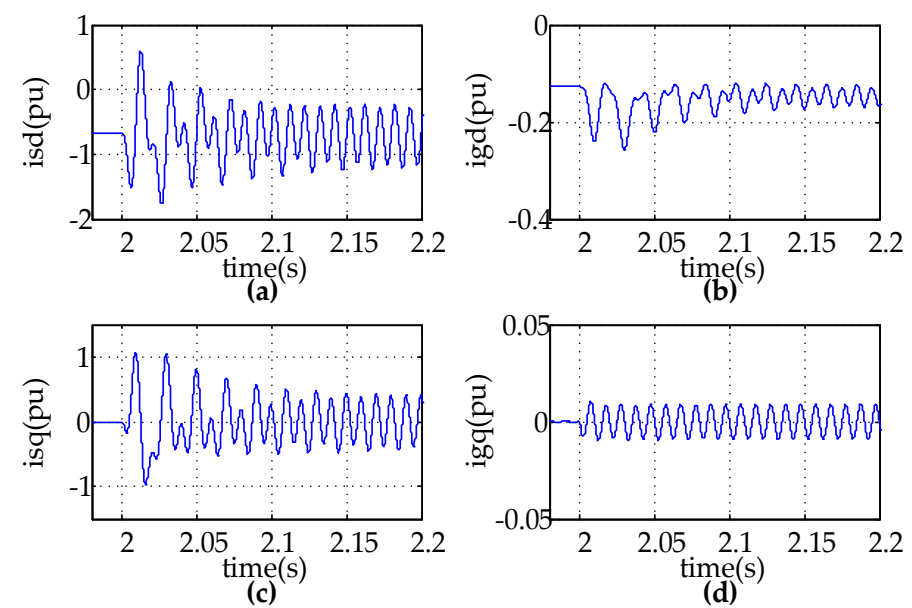

Figure 3. The output current of the DFIG system during grid voltage unbalance: (a) Stator active current; (b) Grid-side converter active current; (c) Stator reactive current; (d) Grid-side converter reactive current.
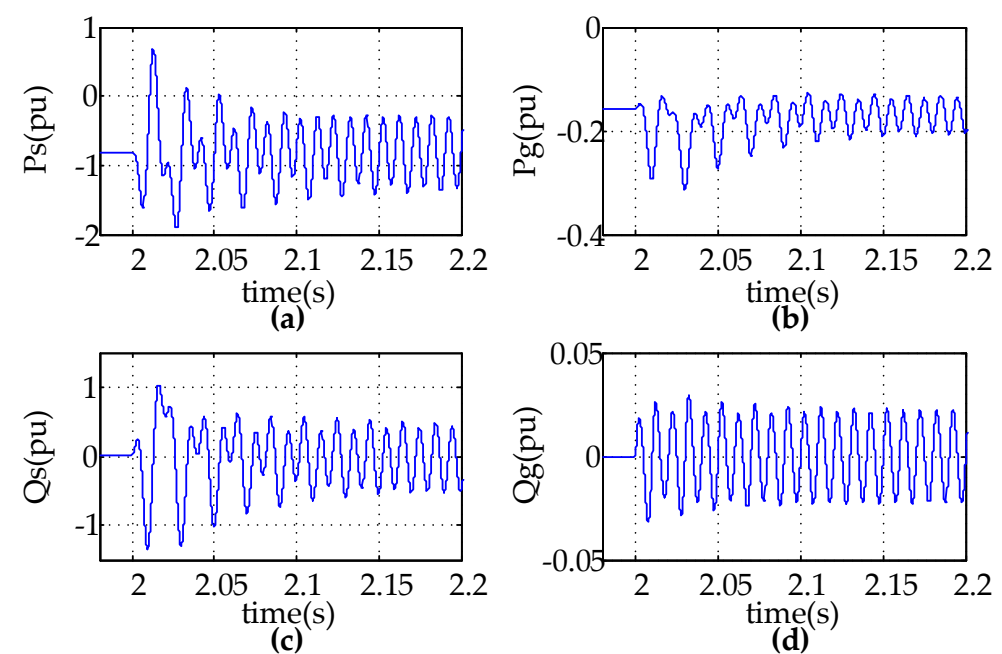

Figure 4. The output power of the DFIG system during grid voltage unbalance: (a) Stator active power; (b) Grid-side converter active power; (c) Stator reactive power; (d) Grid-side converter reactive power.

\subsection{Simulation of IDA-PBC during Unbalanced Grid Voltage Sag/Swell}

Here, the IDA-PBC method under unbalanced grid voltage conditions is compared with PI control and $\mathrm{PBC}$ based on Euler-Lagrange model in the positive and negative synchronous reference frames. According to different control targets of a DFIG system under unbalanced fault conditions, equilibrium points of IDA-PBC are matched. During simulation, three different groups of control targets (suppressing the output current fluctuation, suppressing active power fluctuation, and suppressing reactive power fluctuation of the system, respectively) are applied to validate the feasibility of the IDA-PBC strategy.

\subsubsection{Suppressing the Output Current Fluctuation in a DFIG System}

The control target under unbalanced grid voltage conditions is to suppress double frequency fluctuations in the output current of the stator (active component $i_{\mathrm{sd}}$, reactive component $i_{\mathrm{sq}}$ ) and 
the output current of the grid-side converter (active component $i_{\mathrm{gd}}$, reactive component $i_{\mathrm{gq}}$ ) so that the DIFG system can export a total current that is stable and balanced. Therefore, $i_{\mathrm{sd}-}^{-}$and $i_{\mathrm{sq}-}^{-}$in Equation (18) as well as $i_{\mathrm{gd}-}^{-}$and $i_{\mathrm{gq}-}^{-}$in Equation (19) are set to zero; then expectations of current at desired equilibrium points $x_{\mathrm{R}}^{*}$ and $x_{\mathrm{G}}^{*}$ of the system are:

$$
\left\{\begin{array}{l}
i_{\mathrm{rd}+}^{+*}=-\frac{L_{\mathrm{s}} P_{\mathrm{s} 0}^{*}}{L_{\mathrm{m}} u_{\mathrm{sd}+}^{+}} \\
i_{\mathrm{rq}+}^{+*}=-\frac{u_{\mathrm{sd}+}^{+}}{L_{\mathrm{m}} \omega_{1}}+\frac{L_{\mathrm{s}} Q_{\mathrm{s} 0}^{*}}{L_{\mathrm{m}} u_{\mathrm{sd}+}^{+}} \\
i_{\mathrm{rd}-}^{-*}=-\frac{u_{\mathrm{sq}-}^{-}}{L_{\mathrm{m}} \omega_{1}} \\
i_{\mathrm{rq}-}^{-*}=\frac{u_{\mathrm{sd}-}^{-}}{L_{\mathrm{m}} \omega_{1}} \\
i_{\mathrm{gd}+}^{+*}=\frac{P_{\mathrm{g} 0}^{*}}{u_{\mathrm{gd}+}^{+}} \\
i_{\mathrm{gq}+}^{+*}=-\frac{Q_{\mathrm{g} 0}^{*}}{u_{\mathrm{gd}+}^{+}} \\
i_{\mathrm{gd}-}^{-*}=0 \\
i_{\mathrm{gq}-}^{-*}=0
\end{array}\right.
$$

Simulation waves in the positive and negative synchronous reference frames under PI control, PBC based on Euler-Lagrange model and IDA-PBC based on PCHD model are shown in Figure 5. It is evident that irrespective of whether there is unbalanced grid voltage sag or swell, the IDA-PBC method effectively suppresses double frequency fluctuations of the stator output current as well as the grid-side converter output current to ensure a balanced total output current in the DFIG system. Compared to PI control and PBC based on Euler-Lagrange model in the positive and negative synchronous reference frames, it removes oscillation of each current faster and applies a shorter modulation process so that the DFIG system can reach a new stable status more quickly. In addition, because IDA-PBC has more configuration parameters compared with PBC based on Euler-Lagrange model, the system using IDA-PBC can be controlled more finely. Moreover, the structure of DFIG is more complex than the structure of the grid-side converter, so there are more configuration parameters in the IDA-PBC law of DFIG compared with those in the IDA-PBC law of grid-side converter. Therefore, the control optimization of the DFIG is more obvious than the grid-side converter based on IDA-PBC.
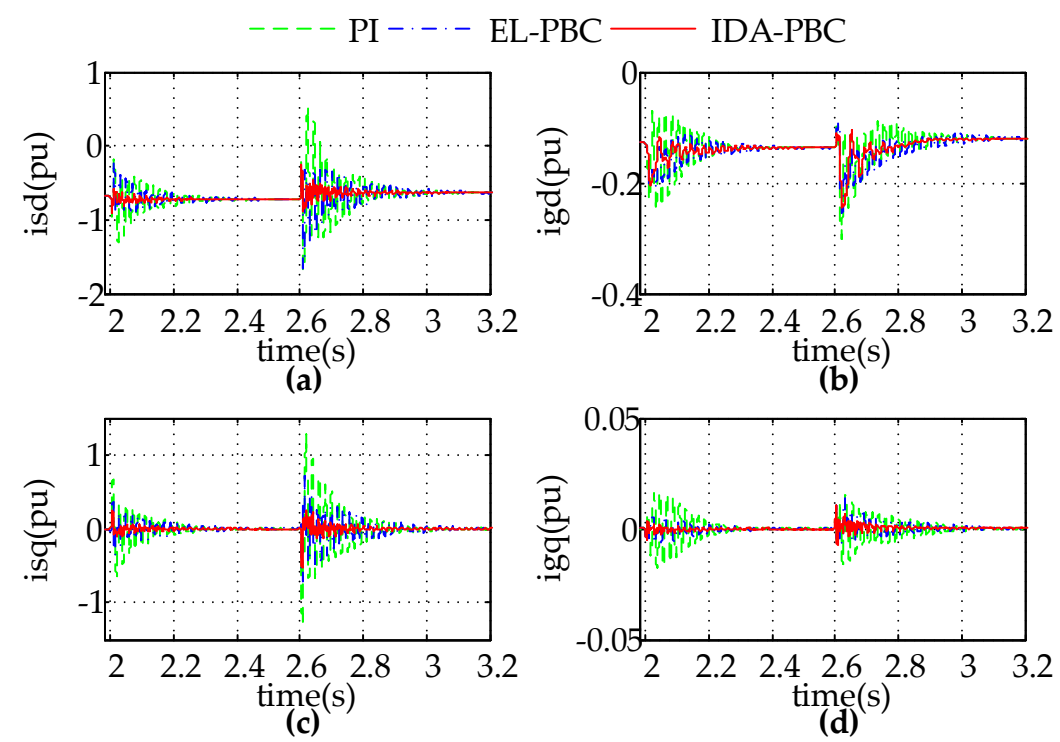

Figure 5. Suppressing the output current fluctuation: (a) Stator active current; (b) Grid-side converter active current; (c) Stator reactive current; (d) Grid-side converter reactive current. 


\subsubsection{Suppressing Output Active Power Fluctuation in a DFIG System}

The control target during grid voltage unbalance is to suppress double frequency pulsations of active power $P_{\mathrm{S}}$ of the stator and active power $P_{\mathrm{g}}$ of the grid-side converter so that the DIFG system can export a balanced total active power under fault conditions. At this time, $P_{\mathrm{ssin} 2}$ and $P_{\mathrm{scos} 2}$ in Equation (18) as well as $P_{\text {gsin2 } 2}$ and $P_{\text {gcos2 } 2}$ in Equation (19) are desired to be zero, so expectations of each current in desired equilibrium points $x_{\mathrm{R}}^{*}$ and $x_{\mathrm{G}}^{*}$ of the system should be:

$$
\left\{\begin{array}{l}
i_{\mathrm{rd}+}^{+*}=-\frac{L_{\mathrm{s}} P_{\mathrm{s} 0}^{*} u_{\mathrm{sd}+}^{+}}{L_{\mathrm{m}} D_{1}} \\
i_{\mathrm{rq}+}^{+*}=-\frac{u_{\mathrm{sd}+}^{+}}{L_{\mathrm{m}} \omega_{1}}+\frac{L_{\mathrm{s}} Q_{\mathrm{s} 0}^{*} u_{\mathrm{sd}+}^{+}}{L_{\mathrm{m}} D_{2}} \\
i_{\mathrm{rd}-}^{-*}=-\frac{u_{\mathrm{sq}}-}{L_{\mathrm{m}} \omega_{1}}+\frac{L_{\mathrm{s}} P_{\mathrm{s} 0}^{*} u_{\mathrm{sd}-}^{-}}{L_{\mathrm{m}} D_{1}}-\frac{L_{\mathrm{s}} Q_{\mathrm{s} 0}^{*} u_{\mathrm{sq}-}^{-}}{L_{\mathrm{m}} D_{2}} \\
i_{\mathrm{rq}-}^{-*}=\frac{u_{\mathrm{sd}}^{-}-}{L_{\mathrm{m}} \omega_{1}}+\frac{L_{\mathrm{s}} P_{\mathrm{s}}^{*} u_{\mathrm{sq}}^{-}}{L_{\mathrm{m}} D_{1}}+\frac{L_{\mathrm{s}} Q_{\mathrm{s} 0}^{*} u_{\mathrm{sd}-}^{-}}{L_{\mathrm{m}} D_{2}} \\
i_{\mathrm{gd}+}^{+*}=\frac{u_{\mathrm{gd}+}^{+} P_{\mathrm{g} 0}^{*}}{D_{1}} \\
i_{\mathrm{gq}+}^{+*}=-\frac{u_{\mathrm{gd}+}^{+} Q_{\mathrm{g} 0}^{*}}{D_{2}} \\
i_{\mathrm{gd}-}^{-*}=-\frac{u_{\mathrm{gd}} P_{\mathrm{g} 0}^{*}}{D_{1}}+\frac{u_{\mathrm{gq}}^{-} Q_{\mathrm{g} 0}^{*}}{D_{2}} \\
i_{\mathrm{gq}-}^{-*}=-\frac{u_{\mathrm{gq}-} P_{\mathrm{g} 0}^{*}}{D_{1}}-\frac{u_{\mathrm{gd}}-Q_{\mathrm{g} 0}^{*}}{D_{2}}
\end{array}\right.
$$

where $D_{1}=u_{\mathrm{sd}+}^{+2}-u_{\mathrm{sd}-}^{-2}-u_{\mathrm{sq}-}^{-2}, D_{2}=u_{\mathrm{sd}+}^{+2}+u_{\mathrm{sd}-}^{-2}+u_{\mathrm{sq}-}^{-2}$.

Simulation waves in the positive and negative synchronous reference frames under PI control, PBC based on Euler-Lagrange model and IDA-PBC based on PCHD model are shown in Figure 6. By comparing these three control methods, it can be seen that IDA-PBC effectively suppresses double frequency pulsations of active power of the stator and grid-side converter under fault conditions so that the DFIG system can provide balanced active power to the grid. Furthermore, IDA-PBC is quicker in response and generates smaller active power oscillations in the stator and grid-side converter during the transition process.

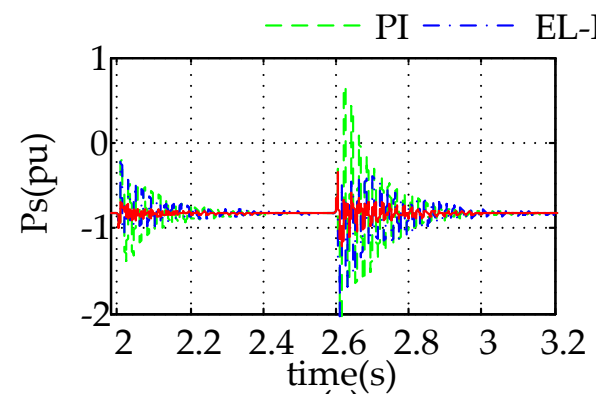

(a)

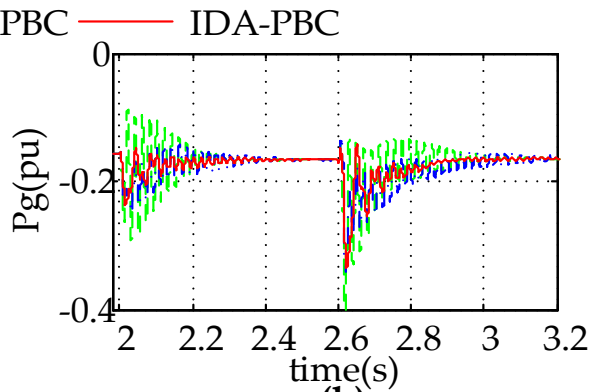

(b)

Figure 6. Suppressing the output active power fluctuation: (a) Stator active power; (b) Grid-side converter active power.

\subsubsection{Suppressing Output Reactive Power Fluctuation in a DFIG System}

Here, the control target under unbalanced grid voltage conditions is to suppress double frequency oscillations of the stator reactive power $Q_{\mathrm{s}}$ and the grid-side converter reactive power $Q_{\mathrm{g}}$ so that the DIFG system can export a balanced total reactive power under fault conditions. Since $Q_{\mathrm{ssin} 2}$ and $Q_{\mathrm{scos} 2}$ in Equation (18) as well as $Q_{\mathrm{ssin} 2}$ and $Q_{\mathrm{scos} 2}$ in Equation (19) are set to zero, expectations of current in desired equilibrium points $x_{\mathrm{R}}^{*}$ and $x_{\mathrm{G}}^{*}$ of the system are: 


$$
\left\{\begin{array}{l}
i_{\mathrm{rd}+}^{+*}=-\frac{L_{\mathrm{s}} P_{\mathrm{s}}^{*} u_{\mathrm{sd}+}^{+}}{L_{\mathrm{m}} D_{2}} \\
i_{\mathrm{rq}+}^{+*}=-\frac{u_{\mathrm{sd}}+}{L_{\mathrm{m}} \omega_{1}}+\frac{L_{\mathrm{s}} Q_{\mathrm{s0}}^{*} u_{\mathrm{sd}+}^{+}}{L_{\mathrm{m}} D_{1}} \\
i_{\mathrm{rd}-}^{-*}=-\frac{u_{\mathrm{sq}}^{-}-}{L_{\mathrm{m}} \omega_{1}}-\frac{L_{\mathrm{s}} P_{\mathrm{s} 0}^{*} u_{\mathrm{sd}-}^{-}}{L_{\mathrm{m}} D_{2}}+\frac{L_{\mathrm{s}} Q_{\mathrm{s} 0}^{*} u_{\mathrm{sq}-}^{-}}{L_{\mathrm{m}} D_{1}} \\
i_{\mathrm{rq}-}^{-*}=\frac{u_{\mathrm{sd}}^{-}-}{L_{\mathrm{m}} \omega_{1}}-\frac{L_{\mathrm{s}} P_{\mathrm{s}}^{*} u_{\mathrm{sq}}^{-}}{L_{\mathrm{m}} D_{2}}-\frac{L_{\mathrm{s}} Q_{\mathrm{s0}}^{*} u_{\mathrm{sd}-}^{-}}{L_{\mathrm{m}} D_{1}} \\
i_{\mathrm{gd}+}^{+*}=\frac{u_{\mathrm{gd}+}^{+} P_{\mathrm{g} 0}^{*}}{D_{2}} \\
i_{\mathrm{gq}+}^{+*}=-\frac{u_{\mathrm{gd}}+Q_{\mathrm{g} 0}^{*}}{D_{1}} \\
i_{\mathrm{gd}-}^{-*}=\frac{u_{\mathrm{gd}-}^{-} P_{\mathrm{g} 0}^{*}}{D_{2}}-\frac{u_{\mathrm{gq}-}^{-} Q_{\mathrm{g} 0}^{*}}{D_{1}} \\
i_{\mathrm{gq}-}^{-*}=\frac{u_{\mathrm{gq}-}^{-} P_{\mathrm{g} 0}^{*}}{D_{2}}+\frac{u_{\mathrm{gd}-}^{-} Q_{\mathrm{g} 0}^{*}}{D_{1}}
\end{array}\right.
$$

Simulation waves in the positive and negative synchronous reference frames under PI control, PBC based on Euler-Lagrange model and IDA-PBC are shown in Figure 7. From those figures, it can be concluded that IDA-PBC can effectively suppress double frequency oscillations of reactive power of the stator and grid-side converter under fault conditions to ensure reactive power balance of the DFIG system in grid-connected mode. Compared to PI control and PBC based on Euler-Lagrange model in the positive and negative synchronous reference frames, the IDA-PBC method reduces reactive power oscillation of the stator and grid-side converter, and the transition process is also shortened.

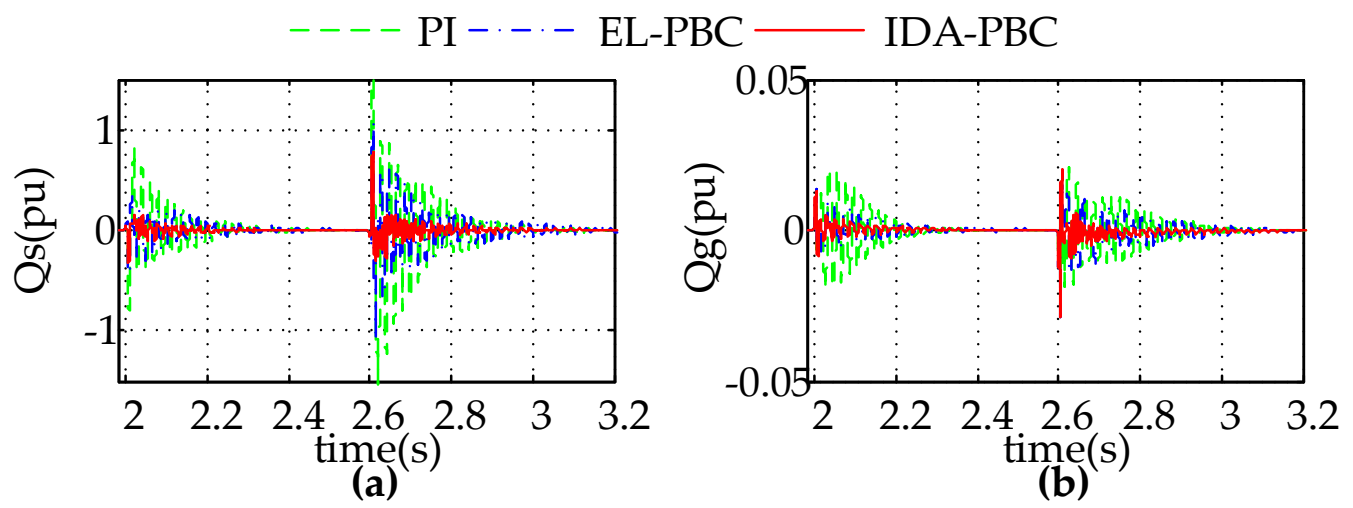

Figure 7. Suppressing the output reactive power fluctuation: (a) Stator reactive power; (b) Grid-side converter reactive power.

\section{Conclusions}

PBC theory is a method to analyze and control a system from the perspective of energy. Compared with PBC based on Euler-Lagrange model, IDA-PBC based on the PCHD model can reflect the details of system better, and there are more configuration parameters in IDA-PBC laws, so systems using IDA-PBC can be controlled more effectively. Furthermore, especially for complex systems, the advantage of the IDA-PBC method is more obvious. This paper establishes a PCHD model of a DFIG system under unbalanced grid voltage conditions and applies an IDA-PBC strategy. Regarding different control targets under fault conditions, desired equilibrium points of the IDA-PBC law are set to coordinate and control the rotor-side converter and grid-side converter. Simulation results indicate that the IDA-PBC method can effectively suppress fluctuations of output current, active power, and reactive power of the DFIG system under unbalanced grid voltage sag/swell. Compared to PI control and PBC based on the Euler-Lagrange model in the positive and negative synchronous reference frames, the response of the IDA-PBC method is quicker, and suppression of oscillations 
during transient process is more obvious, which significantly improves the continuous operation capability of the DFIG system during grid voltage unbalance.

Author Contributions: Jiawei Huang, the main author of this work, has been counseled by Honghua Wang and Chong Wang.

Conflicts of Interest: The authors declare no conflict of interest.

\section{References}

1. Blaabjerg, F.; Ma, K. Future on power electronics for wind turbine systems. IEEE Trans. Emerg. Sel. Top. Power Electron. 2013, 1, 139-152. [CrossRef]

2. Cardenas, R.; Pena, R.; Alepuz, S.; Asher, G. Overview of control systems for the operation of DFIGs in wind energy applications. IEEE Trans. Ind. Electron. 2013, 60, 2776-2798. [CrossRef]

3. Oliveira, F.; Amorim, A.; Encarnação, L.; Fardin, J.; Orlando, M.; Silva, S.; Simonetti, D. Enhancing LVRT of DFIG by using a superconducting current limiter on rotor circuit. Energies 2016, 9, 16. [CrossRef]

4. Yazhou, L.; Mullane, A.; Lightbody, G.; Yacamini, R. Modeling of the wind turbine with a doubly fed induction generator for grid integration studies. IEEE Trans. Energy Convers. 2006, 21, 257-264.

5. Yu, S.; Fernando, T.; Emami, K.; Iu, H.H.C. Dynamic state estimation based control strategy for DFIG wind turbine connected to complex power systems. IEEE Trans. Power Syst. 2017, 32, 1272-1281. [CrossRef]

6. Wessels, C.; Gebhardt, F.; Fuchs, F.W. Fault ride-through of a DFIG wind turbine using a dynamic voltage restorer during symmetrical and asymmetrical grid faults. IEEE Trans. Power Electron. 2011, 26, 807-815. [CrossRef]

7. Tanvir, A.; Merabet, A.; Beguenane, R. Real-time control of active and reactive power for doubly fed induction generator (DFIG)-based wind energy conversion system. Energies 2015, 8, 10389-10408. [CrossRef]

8. Lima, F.K.A.; Luna, A.; Rodriguez, P.; Watanabe, E.H.; Blaabjerg, F. Rotor voltage dynamics in the doubly fed induction generator during grid faults. IEEE Trans. Power Electron. 2010, 25, 118-130. [CrossRef]

9. Li, J.; Yao, J.; Zeng, X.; Liu, R.; Xu, D.; Wang, C. Coordinated control strategy for a hybrid wind farm with DFIG and PMSG under symmetrical grid faults. Energies 2017, 10, 669. [CrossRef]

10. Hu, J.; Nian, H.; Xu, H.; He, Y. Dynamic modeling and improved control of DFIG under distorted grid voltage conditions. IEEE Trans. Energy Convers. 2011, 26, 163-175. [CrossRef]

11. Hu, J.; He, Y. Reinforced control and operation of DFIG-based wind-power-generation system under unbalanced grid voltage conditions. IEEE Trans. Energy Convers. 2009, 24, 905-915. [CrossRef]

12. Li, R.; Geng, H.; Yang, G. Asymmetrical high voltage ride through control strategy of grid-side converter for grid-connected renewable energy equipment. In Proceedings of the 2014 International Power Electronics and Application Conference and Exposition, Shanghai, China, 5-8 November 2014; pp. 496-501.

13. Fang, Y.; Sun, D.; Xiong, P. A coordinated control strategy of DFIG-based WECS for high voltage ride-through enhancement. In Proceedings of the 2014 17th International Conference on Electrical Machines and Systems (ICEMS), Hangzhou, China, 22-25 October 2014; pp. 2808-2814.

14. Xie, Z.; Shi, Q.; Song, H.; Zhang, X.; Yang, S. High voltage ride through control strategy of doubly fed induction wind generators based on active resistance. In Proceedings of the 2012 7th International Power Electronics and Motion Control Conference (IPEMC), Harbin, China, 2-5 June 2012; pp. 2193-2196.

15. Ortega, R.; Perez, J.A.L.; Nicklasson, P.J.; Sira-Ramirez, H. Passivity-Based Control of Euler-Lagrange Systems: Mechanical, Electrical and Electromechanical Applications; Springer: Berlin, Germany, 2013.

16. Xue, H.; Wang, Y.; Yang, F. Adaptive passivity-based control strategies of doubly fed induction wind power generator systems. In Proceedings of the 2nd International Symposium on Power Electronics for Distributed Generation Systems, Hefei, China, 16-18 June 2010; pp. 731-734.

17. Zheng, X.; Ren, Y.; Wang, C. Passivity-based control scheme for doubly-fed induction generator under unbalanced grid voltage. In Proceedings of the 2nd IET Renewable Power Generation Conference (RPG 2013), Beijing, China, 9-11 September 2013; pp. 1-8.

18. Seleme, S.I.; Silva, S.R.; Soares, L.T.L. Stabilization of back-to-back converter in wind generation system connected to the grid: IDA-PBC versus PI control. In Proceedings of the 2014 16th European Conference on Power Electronics and Applications (EPE'14-ECCE Europe), Lappeenranta, Finland, 26-28 August 2014; pp. 1-8. 
19. Qu, Y.B.; Song, H.H. Energy-based modelling and control of wind energy conversion system with DFIG. Int. J. Control 2011, 84, 2035-2045. [CrossRef]

20. Lopez-Garcia, I.; Espinosa-Perez, G.; Siguerdidjane, H.; Doria-Cerezo, A. On the passivity-based power control of a doubly-fed induction machine. Int. J. Electr. Power Energy Syst. 2013, 45, 303-312. [CrossRef]

21. López-García, I.; Beltran-Carbajal, F.; Espinosa-Pérez, G.; Escarela-Perez, R. Passivity-based power control of a doubly fed induction generator with unknown parameters. Int. Trans. Electr. Energy Syst. 2016, 26, 2402-2424. [CrossRef]

22. Duindam, V.; Macchelli, A.; Stramigioli, S.; Bruyninckx, H. Modeling and Control of Complex Physical Systems: The Port-Hamiltonian Approach; Springer: Berlin, Germany, 2009.

23. Van der Schaft, A. L2-Gain and Passivity Techniques in Nonlinear Control; Springer: Berlin, Germany, 2017.

24. Xu, L.; Wang, Y. Dynamic modeling and control of DFIG-based wind turbines under unbalanced network conditions. IEEE Trans. Power Syst. 2007, 22, 314-323. [CrossRef]

25. Song, X.-W.; Wang, Y.; Wang, Z.-A. Dual reference frame scheme for distributed generation grid-connected inverter under unbalanced grid voltage conditions. In Proceedings of the 2008 IEEE Power Electronics Specialists Conference, Rhodes, Greece, 15-19 June 2008; pp. 4552-4555.

26. Ortega, R.; Van Der Schaft, A.; Maschke, B.; Escobar, G. Interconnection and damping assignment passivity-based control of port-controlled Hamiltonian systems. Automatica 2002, 38, 585-596. [CrossRef]

27. Hu, J.; He, Y.; Xu, L.; Williams, B.W. Improved control of DFIG systems during network unbalance using PI-R current regulators. IEEE Trans. Ind. Electron. 2009, 56, 439-451. [CrossRef]

(C) 2017 by the authors. Licensee MDPI, Basel, Switzerland. This article is an open access article distributed under the terms and conditions of the Creative Commons Attribution (CC BY) license (http://creativecommons.org/licenses/by/4.0/). 